\title{
El nacimiento de una comunidad
}

Por una serie de razones, ajenas todas ellas a la voluntad de quienes confeccionamos esta revista, el presente número de Isegoria acude con algún retraso a su cita habitual con los lectores. A la satisfacción de ver superados los obstáculos que impusieron dicho retraso, se une ahora la de poder hacemos eco en las páginas que siguen de la celebración del Primer Congreso Iberoamericano de Filosofia (Cáceres-Madrid, 21-26 de septiembre de 1998). Para una revista como Isegoría, que siempre ha hecho proclamación de su vocación iberoamericanista, semejante reunión constituía un acontecimiento de la mayor trascendencia, acontecimiento que en modo alguno cabria pasar por alto.

El Primer Congreso Iberoamericano de Filosofia representa el acta de nacimiento de una comunidad filosófica, de cuya gestación venianse registrando abundantes indicios desde bastante tiempo atrás. De entre los más recientes, bastaria mencionar la puesta en marcha de una obra común de la envergadura de la Enciclopedia Iberoamericana de Filosofia, asi como la publicación en el curso de la última década de una nutrida serie de volümenes colecivos - para no citar sino algunos de esos volumenes, volumenes en este caso de homenaje a varios miembros insignes de aquella comunidad, ahi están los dedicados entre otros a Adolfo Sánchez Vázquez (J. González-C. Pereyra-G. Vargas Lozano, eds., Praxis y filosofía, México-Barcelona-Bs. Aires, 1985), Arturo Andrés Roig ( $H$. Cerutti-M. Rodríguez Lapuente, eds., Filosofía e historia de las ideas, Guadalajara, México, 1989), Francisco Miró Quesada (D. Sobrevilla-D. García Belaunde, eds., Lógica, razón y humanismo, Lima, 1992), Ernesto Garzón Valdés (W. Krawietz-G. H. von Wright, eds., Öffentliche oder private Moral?, Berlín, 1992), Luis Villoro (E. Garzón-F. Salmerón, eds. Epistemología y cultura, México, 1993) o Fernando Salmerón (L. Olivé-L. Villoro, eds., Filosofía moral, educación e historia, México, 1996) — donde filósofos latinoamericanos y peninsulares, amén de los procedentes de otras latitudes, entremezclan sus firmas, dejando así constancia de los estrechos lazos, tanto profesionales como personales, que les mantienen religados. Pero, por lo demás, los españoles podemos sentimos legitimamente orgullosos de la destacada contribución prestada por nuestro exilio filosófico, hace ya más de medio siglo, a la consolidación de tales vínculos, y es de justicia consignar que la patemidad de la idea misma de este Primer Congreso Iberoamericano de Filosofia corresponde a nuestro compatriota José Gaos. 
De ahi que sea un texto styo el que encabece - seguido de los del peruano Augusto Salazar Bondy y el mexicano Fernando Salmerón-la breve antologia de textos, ya clásicos a estas alturas, con que se abre este número. En cuanto a los artículos que integran su cuerpo central, seleccionados de entre las numerosas intervenciones habidas en el Congreso, se muestra en ellos que el imperativo de descubrimos los unos a los otros de José Saramago está lejos de reducirse a un mandato retórico y que la hermosa fábula de la balsa de piedra del Premio Nobel portugués se ha hecho realidad en lo que atañe al menos a nuestro ámbito filosófico, de suerte que el srumbo al Sum del pensamiento peninsular le hace sentirse concernido muy de cerca por las vicisitudes del latinoamericano. El artículo del profesor de la Universidad de San Marcos, Lima, Francisco Miró Quesada comenta la tensión entre "universalismo" y "latinoamericanismo" -esto es, entre la exigencia de respetar la universalidad de los problemas filosóficos y la de atender a la contextualización latinoamericana de sus ptanteamientos-con la autoridad de quien se halla bien familiarizado con los dos polos de la misma, en tanto que el profesor Guillermo Hoyos Vásquez, de la Universidad Nacional de Bogotá, concreta esa tensión bajo la forma de una confrontación entre ética (comunitarista) de la liberación y ética (liberal) del discurso, para acabar proponiendo su resolución en la dirección de una radicalización republicana de la práctica social del «pluralismo razonables que permita la instauración de un «poder comunicativo», plenamente democrático, desde el «uso ético de la razón práctica». Pero dicha tensión entre «lo universal» $y$ «lo particulars, que es hoy por hoy lo que imprime su característica más acusada a la filosofia latinoamericana, resulta de algún modo susceptible de extrapolación a la comunidad filosófica iberoamericana en general, comunidad cuyo reconocimiento como un hecho no excluye la pregunta filosófica acerca de sus condiciones de posibilidad. La respuesta ofrecida a esa pregunta, en la que a no dudarlo fue una de las intervenciones más significativas de todo el Congreso, por el profesor Luis Villoro - del Instituto de Investigaciones Filosóficas de la Universidad Nacional Autónoma de México-, merece un capitulo aparte.

Seguin Villoro, el filosofo iberoamericano ha de rehuir por igual el riesgo del ensimismamiento y el de la alteración. El filósofo *alterado» es aquel cuyo pensamiento gira exclusivamente en tomo a un centro extraño a su propia circunstancia cultural, en tanto que el del "ensimismados se confina con exclusividad dentro de esta última hasta incurrir en una especie de narcisismo etnocéntrico. Y sólo si se salvan ambos escollos, que Villoro interpreta como Escila y Caribdis de la travesía a emprender por la comunidad filosófica iberoamericana, cabria confiar en hacer de ésta una comunidad filosófica auténtica, dispuesta a reconocerse autónomamente en un repertorio de cuestiones compartidas que interesarian en principio a cualquier sujeto racional, mas cuya selección obedece a las necesidades y a los deseos colectivos de esos sujetos en tanto que insertos en un determinado contexto sociohistórico.

Para el lector español, es dificil resistirse a leer la consigna "Ni ensimismamiento ni alteración» de Villoro como una reformulación en negativo del título de Ontega 
"Ensimismamiento y alteración», tras la aparente conjunción de cuyos miembros se disfraza en rigor una disyunción excluyente entre uno y otro. Aun cuando la pareja de conceptos orteguianos recoge dos umomentos» o «dimensiones» igualmente insoslayables de la vida y la condición humanas, lo que se da entre ambos no es una yuxtaposición sino una franca contraposición. Y tampoco sería imposible rastrear en esta última, al margen de las intenciones de Ortega e incluso de su explicita consciencia, la huella de remotos e impensados antecedentes que darian pie tal vez a emparentar la noción de ualteracion" con la marxiana de «alienación» (Entfremdung) o, mejor aún, con la hegeliana de «enajenación» (Entäusserung) que añade a la idea de alienación o «extrañamientos la de «exteriorización», como en el caso del proceso a través del cual la idea o el ser "en sís se exteriorizan en el «fuera de si» o mundo de la otredad para cobrar de esa manera conciencia de si y transformarse en idea o ser upara sí, el verdadero tertium quid, por consiguiente, entre el ensimismamiento y la alteración. Lejos de encerrarse en sí misma, se diría, una comunidad filosófica como la iberoamericana ha de abrirse al mundo exterior y situarse en la perspectiva cosmopolita de la «filosofia mundana», pero para poder cobrar así conciencia más exacta de su problemática identidad y autodeterminarse en la consecución de sus objetivos o, si se nos autorizara la expresión, uparasimismarse». Con lo que la consigna originaria de Villoro vendría a rezar ahora «Ni ensimismamiento ni alteración, sino parasimismamiento".

De la filosofia se ha dicho alguna vez que no tiene patria, y asi es en verdad si nos atenemos a la imposibilidad de que ninguna comunidad agote exhaustivamente todas las potencialidades de la filosofia, que dependen, sin más, de la capacidad del ser humano para plantearse interrogantes. Pero, precisamente por ello, no cabe sostener que la filosofia haya nacido sólo en Grecia o renacido sólo en Alemania - como en los aledaños del Congreso recordaba, frente a la pretensión heideggeriana, la profesora Juliana González-y habría más bien que conceder que tiene y puede tener sin duda muchas patrias, asi como muchos nacimientos y renacimientos. Quizás con el despertar a la vida de una comunidad filosófica como la iberoamericana estemos, sin ir más lejos, asistiendo a uno de ellos...

(Por un venturoso azar, la noticia en nuestra revista de ese acontecimiento coincide con la publicación de las Sextas Conferencias Aranguren, que corrieron en 1997 a cargo del profesor Pedro Cerezo y versaron sobre «Tres paradigmas del pensamiento españolx, a saber, los representados por las figuras de Unamuno, Ortega y Zubiri. Las tres son suficientemente familiares para nuestros colegas latinoamericanos, pero no hay que pensar que la tradición intelectual por ellas integrada tenga necesariamente idéntica significación al otro lado del Atlántico que entre nosotros. En una comunidad filosófica de la formidable amplitud de la nuestra -que se extiende desde la Europa hispánica a la América latina y, dentro de ésta, de México a Argentina o de Chile a Venezuela y el Caribecaben muy diversas tradiciones de pensamiento, y el mutuo conocimiento y la mutua interacción de todas ellas habrán de encargarse de animar la vida de 
esa comunidad, sinviéndole de base para su proyección con vistas al futuro. Pero cada una de dichas tradiciones ha de ser juzgada según sus peculiares merecimientos en el curso de la discusión reciproca, sin que ninguna pueda aspirar antes de ello a recibir un trato privilegiado ni disfrutar de una posición hegemónica. José Luis Aranguren habría estado muy de acuerdo, como a buen seguro lo está Pedro Cerezo, con la idea de que a los fulósofos de nuestro pais nos corresponde más interesarnos por la «latinoamericanidad» de España que por la «hispanidad» de Latinoamérica, y ésa fue la actitud que por parte española presidió la organización del Primer Congreso Iberoamericano de Filosofia y la que en el presente número ha querido reflejar esta revista.) 